\title{
The Influence of Dust and Black Carbon on Clouds, in Africa
}

\author{
Gerard Rushingabigwi ${ }^{1,2 *}$, Jiahua Zhang1, Tarak Bachagha1, Wilson Kalisa ${ }^{1}$, Malak Henchiri' \\ Ali Shahzad1, Philibert Nsengiyumva ${ }^{2}$, Cesar Nduwayo Bugingo ${ }^{2}$ \\ ${ }^{1}$ Department of Computer Science and Technology, Computer Applications in Remote Sensing, Qingdao University, Qingdao, \\ China \\ ${ }^{2}$ Department of Electrical and Electronic Engineering, Electronics and Telecommunication, University of Rwanda, Kigali, Rwanda \\ Email: *gerardrushingabigwi@yahoo.com
}

How to cite this paper: Rushingabigwi, G., Zhang, J.H., Bachagha, T., Kalisa, W., Henchiri, M., Shahzad, A., Nsengiyumva, P. and Bugingo, C.N. (2018) The Influence of Dust and Black Carbon on Clouds, in Africa. Journal of Computer and Communications, 6, 342-352.

https://doi.org/10.4236/jcc.2018.611031

Received: July 29, 2018

Accepted: November 23, 2018

Published: November 30, 2018

\begin{abstract}
The aerosol can change the clouds properties; the clouds, however, affect the normal behavior of aerosol optical depth. Considerable effects arise while the interaction of aerosol and clouds unavoidably encounters the presence of greenhouse gases (GHGs) in atmosphere. This research discusses the influence of two selected aerosol types, on the clouds in Africa, over the selected sub-time series in the years 1980-2018. Sahara desert's dust is mainly constituted by hematite minerals; which, in return, is mainly composed by the iron oxides, a powerful solar and infra-red radiation absorbing matter and thus a strong and direct radiative forcing agent. For that reason, together with the fact that it is windblown over the biggest region that surrounds the desert, dust is one of the strongly considered aerosol in this research. Besides, black carbon (BC), mostly from the anthropogenic biomass burning process in the mid latitude's African savanna, is the second aerosol type selected for this research: it is one of the abundantly available aerosol types and it is one of the strongest atmospheric radiant energy absorbers. For sake of valid and trustworthy results, the data is collected from multiple satellite remote sensing tools and instruments, all targeting the aerosol-cloud interaction and effects. In this research, different measurements were carried out; those are the spatiotemporal averaged cloud cover, the aerosol (dust and $\mathrm{BC}$ ) extinction optical thickness (AOT), the anomaly of aerosol optical depth (AAOD) as well as different scatter plots' correlation analysis. For findings: the direct influence of hydrophilic BC on clouds formation in central African sub-region is experimentally demonstrated; the dust aerosol highly influences the North African sub-region's cloud formation.
\end{abstract}

\section{Keywords}

Aerosol, Africa, Cloud-Aerosol Interaction, Anomaly of Aerosol Optical Depth 


\section{Introduction}

The term aerosol, in this research, is throughout singular; but it stands for the aerosol particles (either solid or gaseous, in general). There exist many types of solid aerosol particles; a few of them are the dust, sea salt and black carbon. A famous gaseous aerosol is the smoke.

Researching on aerosol is enough significant since it has the direct and very significant effects on human health: several toxic elements are associated with Sahara desert's dust [1], which can endanger the respiratory, cardiovascular and brain systems. In particular, the dust storms transport pollutants as metals and pesticides as well as biological components like spores, fungi and bacteria [2].

Besides, though carbon monoxide belongs to the atmospheric chemistry's measurements, the inorganic carbon, the coal dust, the fly ash, the smoke as well as the black carbon are the types of aerosol which generate carbon monoxide (CO), a very dangerous air pollutant gas to the cardiovascular, respiratory and even brain systems [3] [4] [5].

Apart from the direct effects of dust aerosol on health, dust storm is a direct cause of drought. The dust entrainment has been quantitatively surveyed during the West African Sahel's pre-drought period of 1940-1960 and after drought period of 1960-1980. Once the drought was caused, entrainment of dust furthermore increased, which concludes in a connection of dust emission with the wind and the hazard of drought [6].

In fact, there is always an uncertainty of what happens when aerosol particles such as the mist, the smoke and the smog interact with the clouds. But, aerosol cools and warms the atmosphere: as aerosol interacts with the clouds, a variety of physical and chemical changes is triggered in the atmosphere; thus, either the warming or the cooling effects, depending on which aerosol types [7] [8]. Importantly, the black carbon resulting from whatever fire, is the strongest, direct and indirect absorber of solar radiation in the atmosphere [9] [10]. On the other hand, however, the clouds distort the aerosol optical depth, AOD [11]

Knowing the geographic and climate characteristics of Africa, the specific motives of this research are: 1) to investigate the aerosol types in the closest relationship and interaction with the clouds; 2) to study the anomaly of aerosol optical depth (AAOD) in comparison and correlation with surface skin temperature, the aerosol (BC and dust) extinction AOT in comparison and correlation with the cloud fraction, all in in the west and central African sub-regions of interest.

The remaining part of this research work is organized into materials and methods as well as the discussed results. Results are broadly presented in two sub-sections. All the results, compared to the existing literature, are the input to the discussion section.

\section{Methodology and Data Sources}

The aerosol interacts with solar radiation through absorption and scattering; it 
also interacts with terrestrial radiation through absorption, scattering and emission. Aerosol can thus, influence the cloud formation since it serves as the cloud condensation, from which cloud droplets and ice crystals may form. The formation of clouds is briefly illustrated with Figure 1; the aerosol and greenhouse gases (GHGs) are accounted for major parameters [7] [12].

Besides, the GHGs, which contribute to the anomaly of AOD, play a considerable role to the atmospheric warming. Though this research does not concentrate on the details, the main GHGs are methane and carbon dioxide [13].

It is now an opportunity to briefly define some key terms in this manuscript, which would satisfy some readers' needs.

\subsection{The Key Terms in the Research and the Inherent Scientific Knowledge}

- The aerosol optical depth (AOD) or otherwise referred to as aerosol optical thickness (AOT): the measure of an extent to which aerosol, in its different types: haze, smoke, dust, sea salt, etc., obstructs the light transmission through the phenomenon of absorbing or scattering the light; AOD/AOT is distributed within a column of air to the top of the atmosphere [14]. The aerosol optical depth or thickness ( $\mathrm{AOT}=\tau$ ) is the intact extinction coefficient over a vertical column of one unit area, which is mathematically defined in (1).

$$
A O T=\tau=\tau_{s}+\tau_{a}
$$

where: $\tau, \tau_{s}, \tau_{a}$ are the total optical thickness (or otherwise the extinction), that due to scattering and that due to absorption, respectively. The extinction coefficient is thus the fractional radiance loss. The optical thickness along the vertical direction being known as the normal optical thickness, the parameters can be mathematically deduced from the expression in (2).

$$
e^{-\tau / \cos \theta}=\frac{I_{r}}{I_{s}}
$$

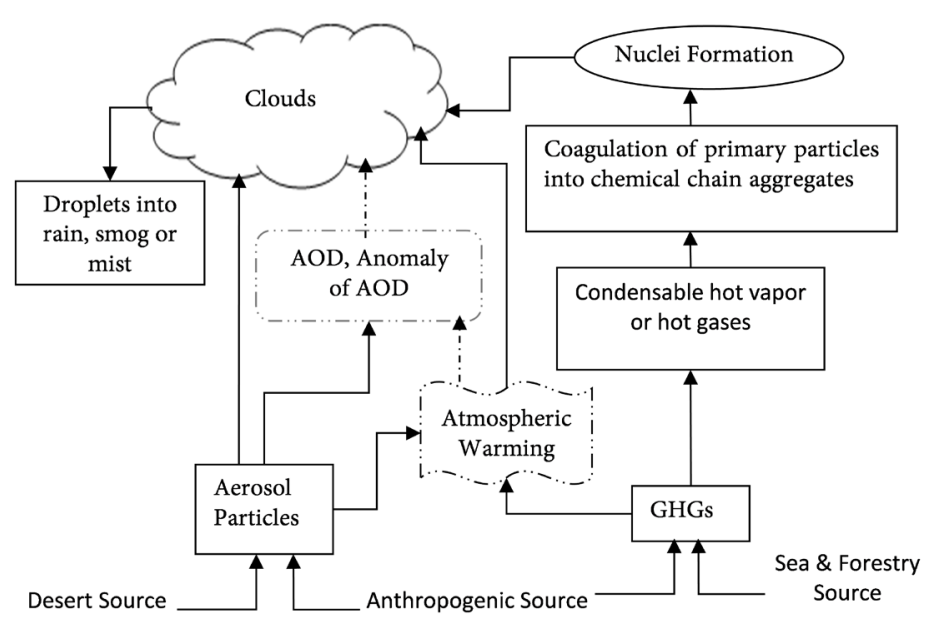

Figure 1. The interaction between clouds, aerosol particles as well as the GHGs. 
$I_{s}$ and $I_{r}$ are the energy at the source of targeted aerosol and the energy back to the remote sensing sensor; $\theta$ is the angle between the sensor and the source of aerosol.

- Extinction: as a process in physics, astronomy and remote sensing, this is the reduction to zero in the intensity of light as it passes through a medium (most notably through the earth's atmospheric particles such as dust), due to absorption, reflection, or/and scattering. In the course of remote sensing, the extinction is measured in terms of extinction coefficient [15].

- The single scattering albedo (SSA): a dimensionless parameter ranging from zero to one, under normal conditions, which evaluates the ration between scattering and extinction in a way, the high albedo indicates either high scattering values or low absorption values [16]. The term albedo itself is the measure of diffusive reflection of solar radiation that is received by a remote sensed body or target.

$$
S S A=\frac{\tau_{s}}{\tau}
$$

- The anomaly of optical depth (AAOD): a measurement encountered when the normal AOD is observed in a strange behavior: the light extinction is along a slant remote sensing path, rather than a vertical (normal) column.

- Albedo: is defined as the fraction of solar radiation reflected by any surface or a target. The snow-covered targets are measured for the high albedo; oceans have the very low albedo [17].

- Black Carbon (BC): is an aerosol type, consisting of soot, charcoal as well as refractory organic matter, which highly absorb light. Directly emitted by the process of incomplete combustion, $\mathrm{BC}$ dwells in the atmosphere up to when taken away via the process dry or wet aerosol deposition. Most important, while $\mathrm{BC}$ is deposited onto the snow and ice, the aerosol enhances the absorption of radiation; it warms the lower atmosphere and accelerates the melting of snow and ice [18].

As the interaction between clouds, aerosols and GHGs is illustrated in Figure 1 , aerosol particles have different sources, of which the desert is the main source. Sahara desert, for instance, is the biggest global source of dust aerosol, which certainly has a very big influence on the global climate change [19]. The other aerosol types such as black carbon, the dust included, come from anthropogenic activities [20]. The figure clearly shows that the aerosol together with the GHGs contribute to the atmospheric warming. The warming of atmosphere causes the abnormal behavior of AOD and of course the warming of the clouds. The clouds were formed through the direct inputs of some aerosol particles together with the nuclei formation due to the coagulated primary particles into chemical chain aggregates from the condensable GHGs' hot vapor. Depending on the nature of aerosol; the process can finally result in the precipitations of different kinds; otherwise the warmest atmosphere causes the lack of precipitation's clearest clouds, leading to droughts. 


\subsection{The Data Source and the Study Region}

The data is collected from multiple remote sensing instruments and tools, as summarized in Figure 2. To ensure the reliability, some of the data, depending on their availability, was collected from the MODerate resolution Imaging Spectro-radiometer on Terra Satellite (MODIS-T) and MERRA-2. MERRA-2 is owned by the Goddard Earth Sciences and Information Services Center (GES-DISC). MERRA-2 directly assimilates and re-analyzes raw data in full from the Moderate-resolution Imaging Spectro-radiometer (MODIS) and the Advanced Very High-Resolution Radiometer, AVHRR. The reanalysis system also retrieves the aerosol optical thickness (AOT) from the aerosol robotic network (AERONET), since January 1980 to date; thus, the MERRA-2 data itself accounts for multiple source [21] [22].

Besides, the Sea-viewing Wide Field of view Sensor (SeaWiFS) as well as the Tropical Rainfall Measuring Mission (TRMM) are jointly utilized for the data which allowed the comparatively study of dust and BC against other different measurements like the AAOD, the surface skin temperature, the cloud fraction as well as the real time precipitation, in at least the west and central sub-regions of Africa.

The entire Africa, roughly coordinated by $18^{\circ} \mathrm{W}, 35^{\circ} \mathrm{S}, 52^{\circ} \mathrm{E}$ and $40^{\circ} \mathrm{N}$, is the region of interest (RoI) for this research. However, the region is actually so big that, basing on the natural climatic conditions, the five subdivisions were created as: 1) the West Africa which is bound as $15^{\circ} \mathrm{W},(4-14)^{\circ} \mathrm{N}, 9.5^{\circ} \mathrm{E}$; 2$)$ the North Africa (and neighboring) which is bound as $\left.10^{\circ} \mathrm{W},(24-40)^{\circ} \mathrm{N}, 52^{\circ} \mathrm{E} ; 3\right)$ the Central Africa which is bound as $\left.(9.5-30)^{\circ} \mathrm{E}, 10^{\circ} \mathrm{S}, 14^{\circ} \mathrm{N} ; 4\right)$ the South Africa which is bound as $(11-35)^{\circ} \mathrm{E},(10-35)^{\circ} \mathrm{S}$; as well as 5) the East Africa which is bound as $(30-52)^{\circ} \mathrm{E}, 35^{\circ} \mathrm{S}, 12^{\circ} \mathrm{N}$.

Besides, the Giovanni's informatics tools were mainly used to collect data [23] [24]; thus, all the instruments and tool reported in Figure 2 are accessed. The results were further treated by the help of the data analysis software tools: the Origin, the Arc GIS and the Google earth software tools.

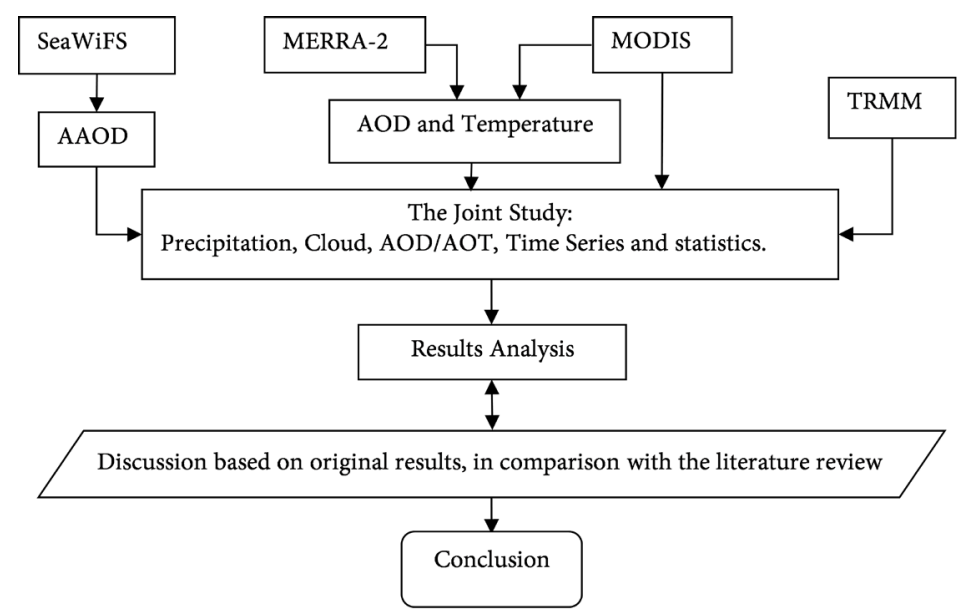

Figure 2. The research bloc diagram concept. 


\section{Results and Discussion}

The preliminary results, as depicted in Figure 3, are the cloud fraction's mean of daily mean, the black carbon extinction AOT, the dust extinction AOT and the real time precipitation's map overlay for April, 2018; shown Figure 3; the data collected from Giovanni platform and further treated by the Arc Map software tool.

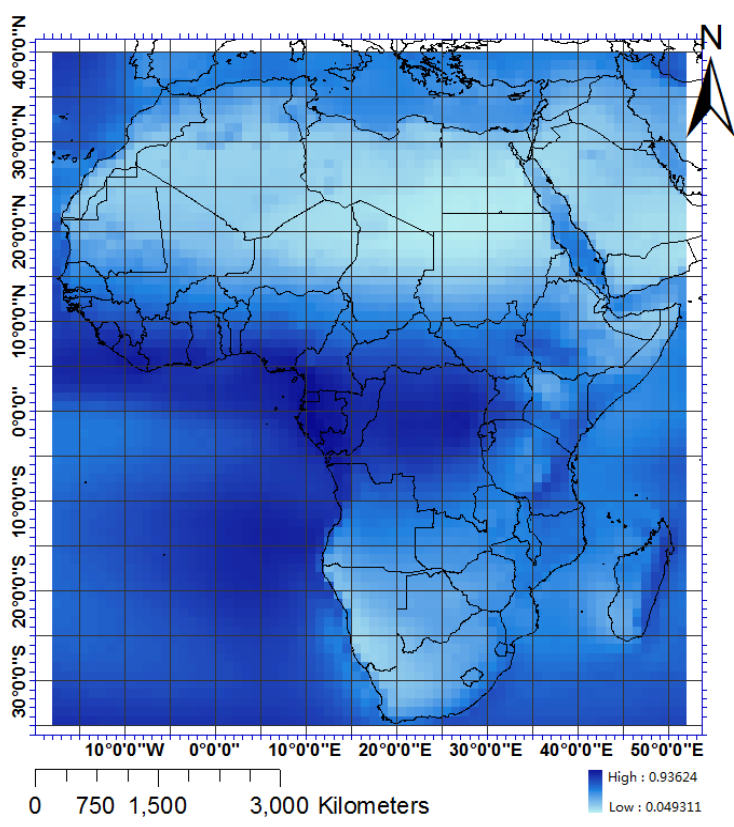

(a)

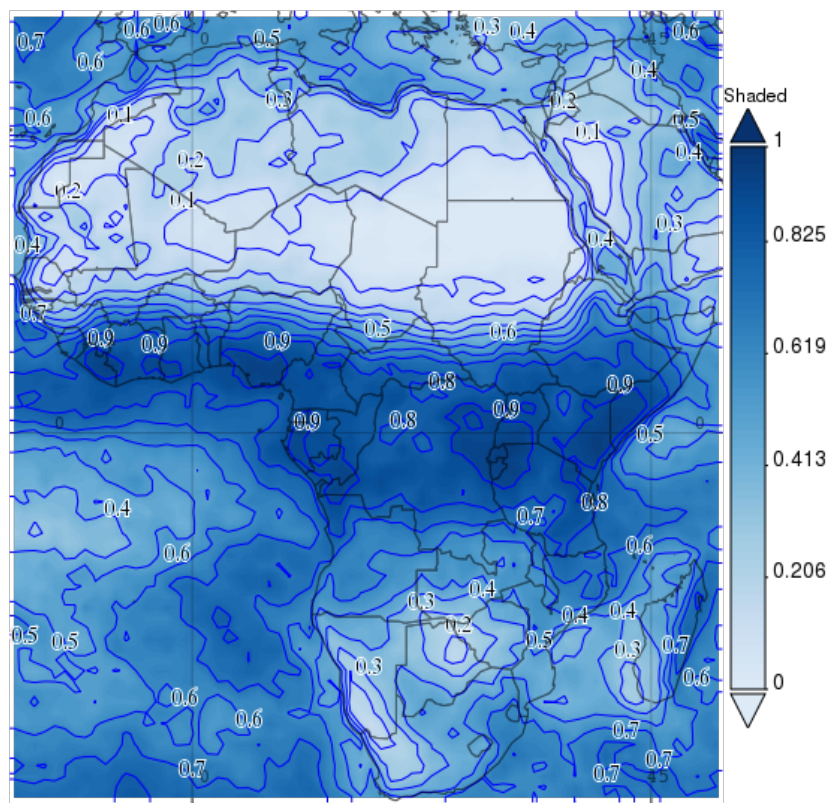

(c)

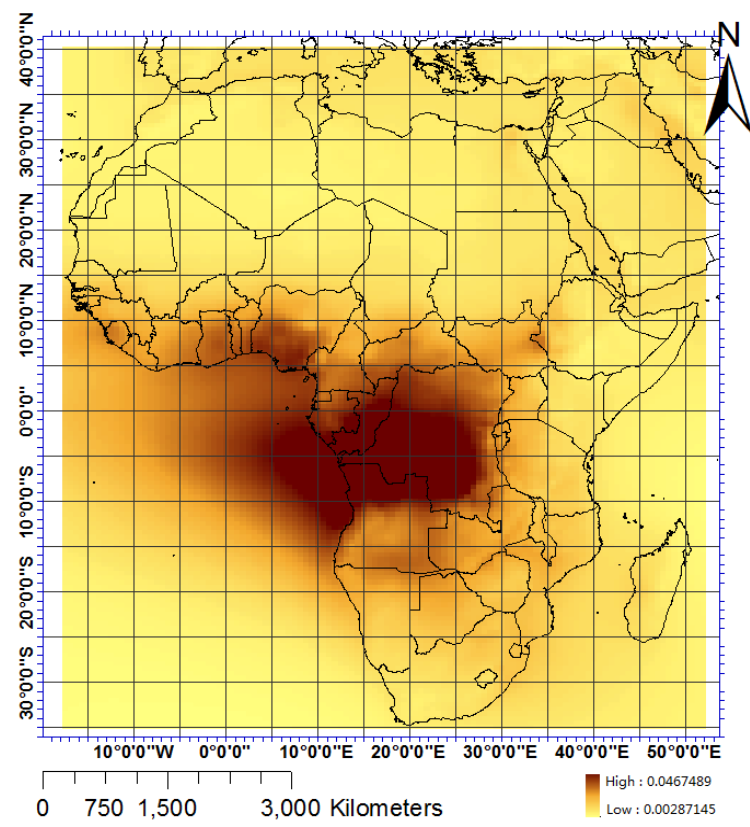

(b)

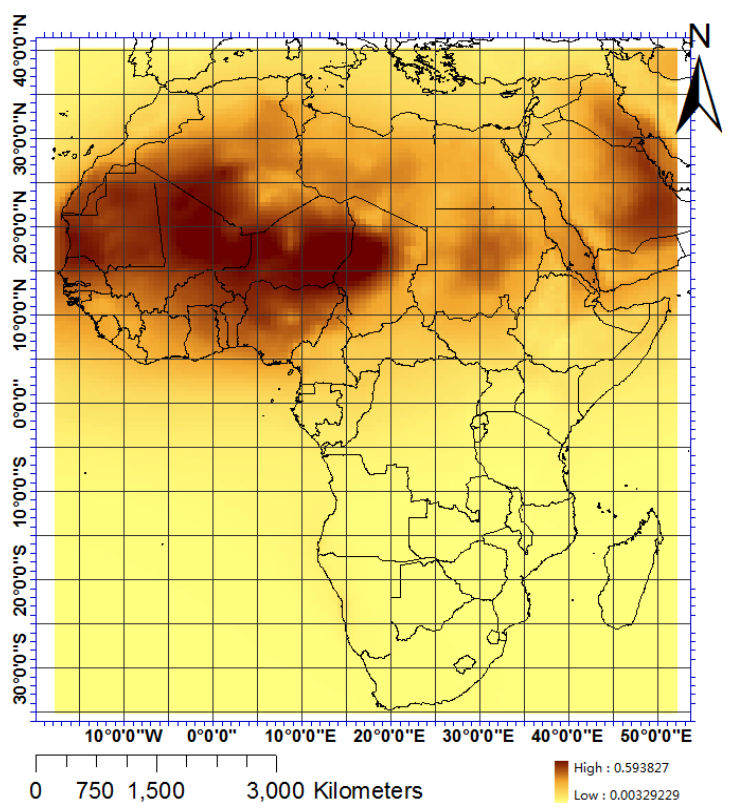

(d)

Figure 3. The preliminary results: (a) The mean of daily mean of the cloud fraction over 2000-2018; (b) The BC extinction AOT over 2000-2018; (c) The real time precipitation's rain map overlay for April, 2018 (Source: https:/giovanni.gsfc.nasa.gov/giovanni/); (d) The dust extinction AOT over 2000-2018. 
The AOD in Africa, is studied over the time series of 1980-2018 in all the seasons and regions. Nonetheless, the main research objective is to study and report the aerosol effects on clouds while there is an increasing AOD, if not its abnormal behavior. Thus, Figure 4 reports the regions and seasons characterized by the highest AOD values; it shows that March-April-Amy (MAM) seasons in the West African sub-region is characterized by the highest AOD, over the sub-temporal resolution of 2010.

The findings in Figure 4 together with the findings in Figure 3 mean that the biggest portion of dust is windblown towards west African sub-region. The heaviest black carbon, the highest cloud cover and the real time precipitation are in the central African sub-RoI. For those reasons, the focal study sub-regions are fixed for the west Africa and the central Africa sub-RoIs.

The results in Figure 5 are based on the two focal sub-regions: West and Central Africa. Those are the scatter plots, which illustrate the effects of the rising surface skin temperature due to the increasing dust and black carbon AOT.

The effects of stepping down of the cloud fraction due to the increasing dust and black carbon AOT (the converse is true), as well as the jointly studied averaged dust AOT, averaged AAOD, averaged cloud fraction and averaged black carbon AOT over the 12 months of the year 2010 in the entire Africa, are illustrated in Figure 6.

\section{Discussion}

The aerosol and cloud are closely interacting; the notable aerosol types are BC [15]. The mixed aerosol types were previously diagnosed for the radiative forcing effects [25]; but, for sake of simplicity and accuracy in research, the results presented in this research focussed on the impact of dust and $\mathrm{BC}$ aerosol types, on clouds.

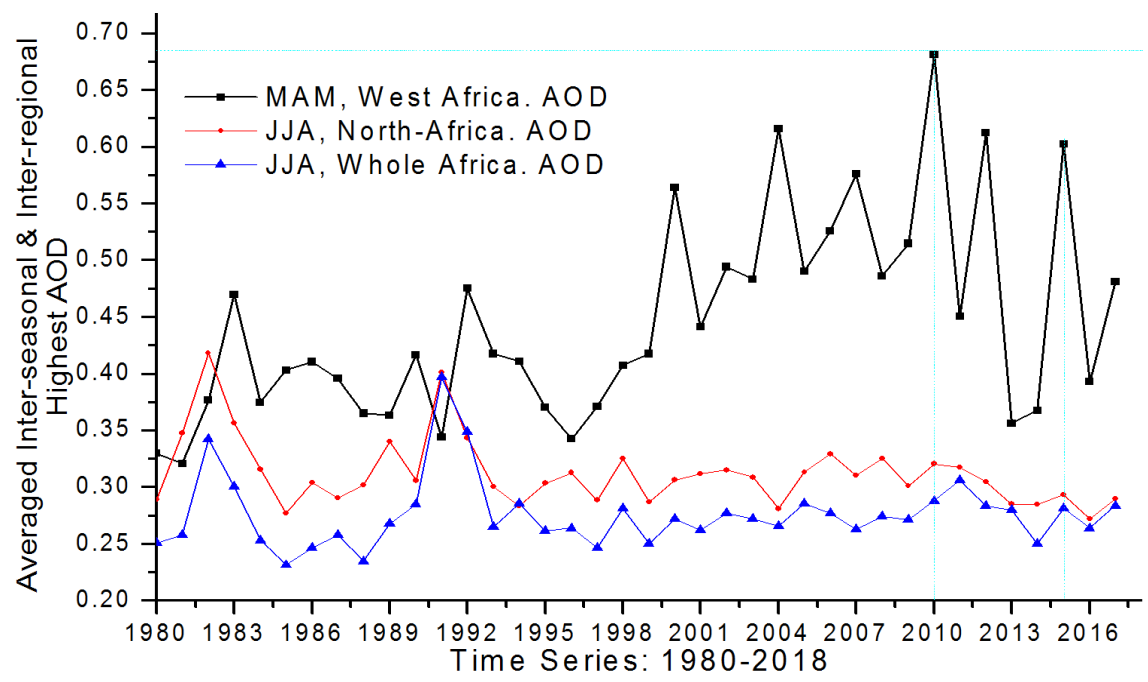

Figure 4. The highest AOD, based on the time series inter-seasonal and inter-regional average. 


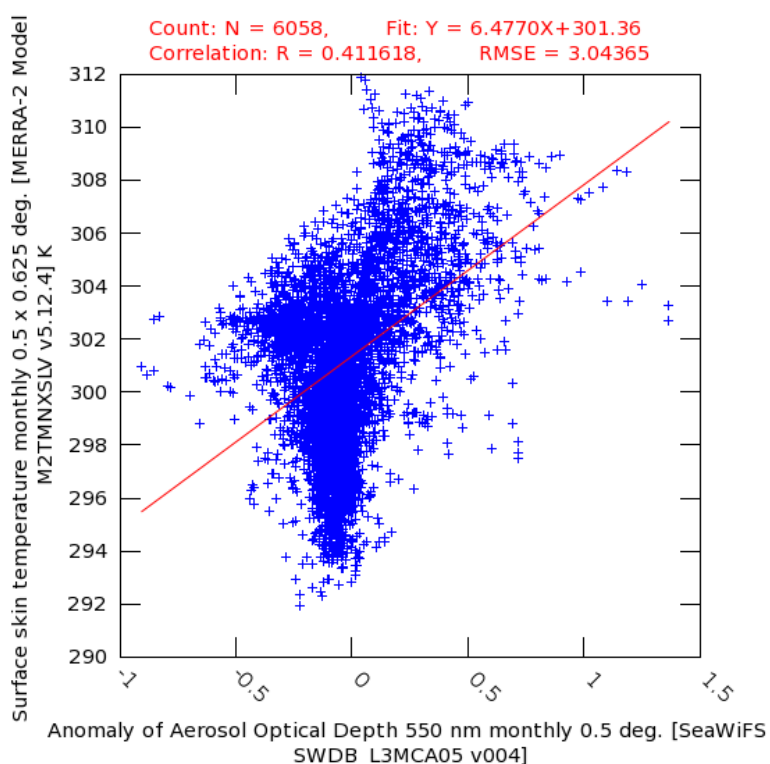

(a)

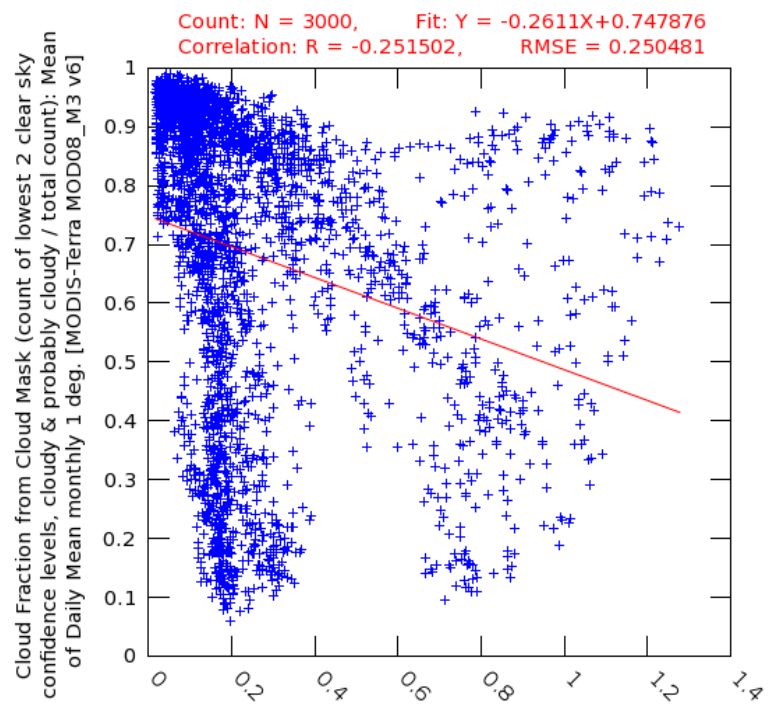

Dust Extinction AOT $550 \mathrm{~nm}$ monthly $0.5 \times 0.625$ deg. [MERRA-2 Model M2TMNXAER v5.12.4]

(c)

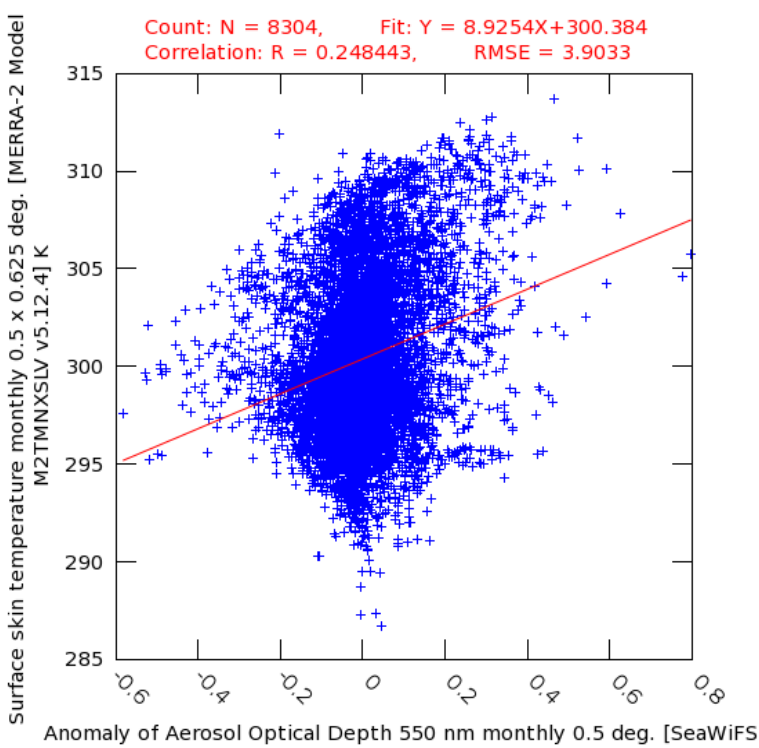

SWDB_L3MCA05 V004]

(b)

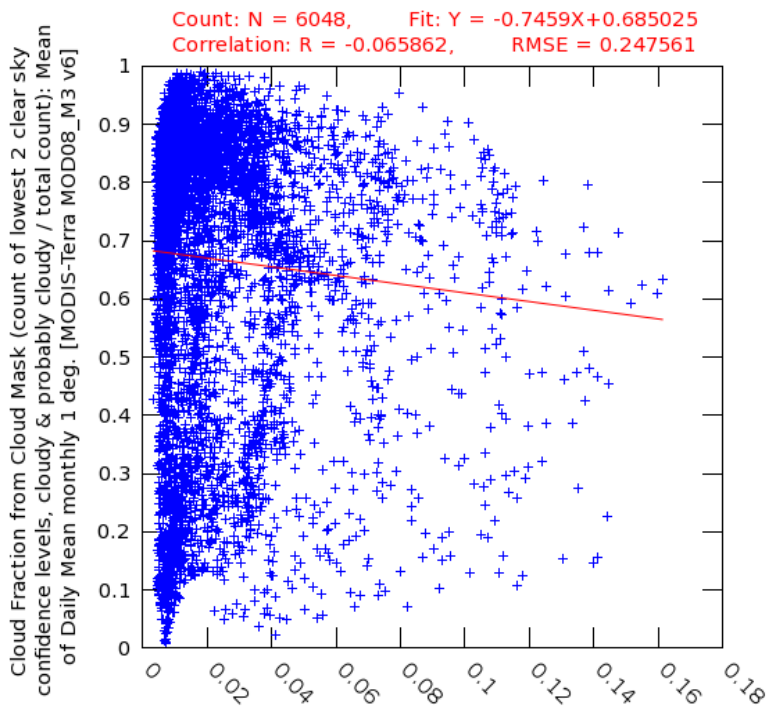

Black Carbon Extinction AOT $550 \mathrm{~nm}$ monthly $0.5 \times 0.625 \mathrm{deg}$ [MERRA-2 Model M2TMNXAER v5.12.4]

d)

Figure 5. The scatter plots (Source: https://giovanni.gsfc.nasa.gov/giovanni/): (a) AAOD against surface skin temperature, in the west African sub-RoI; (b) AAOD against surface skin temperature, in the central African sub-RoI; (c) Dust extinction against the Cloud fraction, in the west African sub-RoI; (d) BC extinction against the Cloud fraction, in the central African sub-RoI.

This research has shown the cloudy central African sub-RoI as well as the coastal regions near to the Gulf of Guinea in a very correlating relationship with the hydrophilic BC, which may act as cloud condensation nuclei [10], due to the mid-latitude's vegetations; hydrophilic BC acts as the cloud nuclei which directly influences the cloud.

On the other hand, the windblown Sahara desert's dust, Figure 3(d), causes the scarcity of clouds and nearly no precipitation's rain as shown in Figure 3(a) and Figure 3(c). 


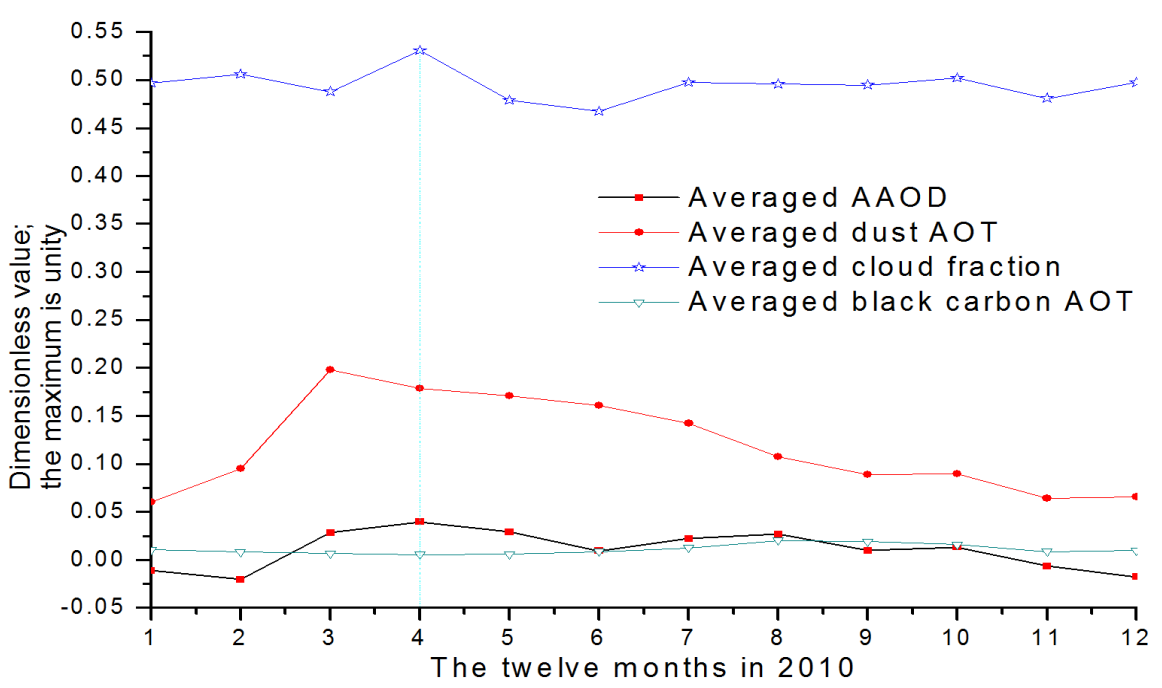

Figure 6. The jointly studied dust AOT, AAOD, cloud fraction and black carbon AOT.

The core and innovation point in this research is manifested, the reference is made from both Figure 5(a) and Figure 5(b), where the averaged AAOD has the rising impact on the surface temperature. Figure 6 demonstrates that the rising AAOD, in April, goes with the remote sensing's rising in the averaged cloud fraction, in Africa.

\section{Conclusion}

The dust and BC warming effects in Africa, are documentable in this research. Technically, the research tool based on multi-satellite and multiple remote sensing instruments is reliable and versatile. Scientifically, different correlations among the focal parameters showed the direct influence of dust and $\mathrm{BC}$ to the warming; which leads to the increase in the AAOD and consequently the deceased cloud cover. The research clarified that, in the whole Africa, the March, April May (MAM) season is always characterized by the heaviest aerosol, as measured from the time series AOD. The month of March is characterized by the highest dust AOT, which was associated with the sudden decrease of cloud cover; the raising AAOD was however associated with the increase of cloud cover, in the Month of April; this is according to the African spatio-tempoaral comparative case study in the year 2010. Inhabitants would reduce the aerosol emission, by controlling their anthopogenic activities which generate aerosol like dust BC, sulfates as well as GHGs like methane; some of these remote sensing measurements are not discussed in this research; they are however input parameters to the next research article.

\section{Acknowledgements}

The University of Rwanda is acknowledged for supporting this research by directly involving the university's academic research members.

To the Goddard Earth Sciences Data and Information Service Center (GES 
DISC) is acknowledged that, via research and documentation, the research and technical team regularly enriches Giovanni with the useful and resourceful data; they exceptionally acknowledged in this manuscript.

This research has been supported by the Government of People's Republic of China, via Qingdao University that we hereby acknowledge. This work is fully supported by "Taishan Scholar" project of Shandong Province and key basic research project of Shandong natural science foundation of China (No. ZR2017ZB0422).

\section{Conflicts of Interest}

The authors declare no conflicts of interest regarding the publication of this paper.

\section{References}

[1] Christopher, S.A. and Jones, T.A. (2010) Satellite and Surface-Based Remote Sensing of Saharan Dust Aerosols. Remote Sensing of Environment, 114, 1002-1007. https://doi.org/10.1016/j.rse.2009.12.007

[2] Díaz, J., Linares, C., Carmona, R., Russo, A., Ortiz, C., Salvador, P. and Trigo, R.M. (2017) Saharan Dust Intrusions in Spain: Health Impacts and Associated Synoptic Conditions. Environmental Research, 156, 455-467.

https://doi.org/10.1016/j.envres.2017.03.047

[3] Guzman, J.A. (2012) Carbon Monoxide Poisoning. Critical Care Clinics, 28, 537-548. https://doi.org/10.1016/j.ccc.2012.07.007

[4] Kao, L.W. and Nañagas, K.A. (2006) Toxicity Associated with Carbon Monoxide. Clinics in Laboratory Medicine, 26, 99-125. https://doi.org/10.1016/j.cll.2006.01.005

[5] Rose, J.J., Wang, L., Xu, Q., McTiernan, C.F., Shiva, S., Tejero, J. and Gladwin, M.T. (2017) Carbon Monoxide Poisoning: Pathogenesis, Management, and Future Directions of Therapy. American Journal of Respiratory and Critical Care Medicine, 195, 596-606. https://doi.org/10.1164/rccm.201606-1275CI

[6] Goudie, A.S. (2014) Desert Dust and Human Health Disorders. Environment International, 63, 101-113. https://doi.org/10.1016/j.envint.2013.10.011

[7] Boucher, O., Randall, D., Artaxo, P., Bretherton, C., Feingold, G. and Zhang, X.Y. (2013) Clouds and Aerosols. Climate Change 2013: The Physical Science Basis. Working Group I Contribution to the Fifth Assessment Report of the Intergovernmental Panel on Climate Change, 571-658.

[8] Todd, M.C. and Cavazos-Guerra, C. (2016) Dust Aerosol Emission over the Sahara during Summertime from Cloud-Aerosol Lidar with Orthogonal Polarization (CALIOP) Observations. Atmospheric Environment, 128, 147-157. https://doi.org/10.1016/j.atmosenv.2015.12.037

[9] Zhuang, B.L., Wang, T.J., Li, S., Liu, J., Talbot, R., Mao, H.T. and Zhang, X.Y. (2014) Optical Properties and Radiative Forcing of Urban Aerosols in Nanjing, China. Atmospheric Environment, 83, 43-52. https://doi.org/10.1016/j.atmosenv.2013.10.052

[10] Zhuang, B., Liu, Q., Wang, T., Yin, C., Li, S., Xie, M. and Mao, H. (2013) Investigation on Semi-Direct and Indirect Climate Effects of Fossil Fuel Black Carbon Aerosol over China. Theoretical and Applied Climatology, 114, 651-672.

https://doi.org/10.1007/s00704-013-0862-8 
[11] Quijano, A.L., Sokolik, I.N. and Toon, O.B. (2000) Radiative Heating Rates and Direct Radiative Forcing by Mineral Dust in Cloudy Atmospheric Conditions. Journal of Geophysical Research, 105, 12207-12219. https://doi.org/10.1029/2000JD900047

[12] Boucher, O. (2015) Atmospheric Aerosols, 9-25.

[13] Dean, J.F., Middelburg, J.J., Röckmann, T., Aerts, R., Blauw, L.G., Egger, M. and Dolman, A.J. (2018) Methane Feedbacks to the Global Climate System in a Warmer World. Reviews of Geophysics, 56, 207-250. https://doi.org/10.1002/2017RG000559

[14] Holben, B.N., Eck, T.F., Slutsker, I., Tanré, D., Buis, J.P., Setzer, A. and Smirnov, A. (1998) AERONET - A Federated Instrument Network and Data Archive for Aerosol Characterization. Remote Sensing of Environment, 66, 1-16. https://doi.org/10.1016/S0034-4257(98)00031-5

[15] Chan, P.W. (2010) Determination of Backscatter-Extinction Coefficient Ratio for LIDAR-Retrieved Aerosol Optical Depth Based on Sunphotometer Data. Remote Sensing, 2, 2127-2135. https://doi.org/10.3390/rs2092127

[16] Basak, S.R., Basak, A.C. and Rahman, M.A. (2015) Impacts of Floods on Forest Trees and Their Coping Strategies in Bangladesh. Weather and Climate Extremes, 7, 43-48. https://doi.org/10.1016/j.wace.2014.12.002

[17] Enomoto, T. (2007) Ocean Surface Albedo in AFES. JAMSTEC Rep. R\&D, 6, 21-30. http://www.godac.jamstec.go.jp/catalog/data/doc_catalog/media/JAM_RandD06_02 .pdf

[18] Dou, T.F. and Xiao, C.D. (2016) An Overview of Black Carbon Deposition and Its Radiative Forcing over the Arctic. Advances in Climate Change Research, 7, 115-122. https://doi.org/10.1016/j.accre.2016.10.003

[19] Friese, C.A., Van Hateren, J.A., Vogt, C., Fischer, G. and Stuut, J.B.W. (2017) Seasonal Provenance Changes in Present-Day Saharan Dust Collected in and off Mauritania. Atmospheric Chemistry and Physics, 17, 10163-10193.

https://doi.org/10.5194/acp-17-10163-2017

[20] Wang, C. (2007) Impact of Direct Radiative Forcing of Black Carbon Aerosols on Tropical Convective Precipitation. Geophysical Research Letters, 34, 1-6. https://doi.org/10.1029/2006GL028416

[21] Bosilovich, M., Akella, S., Coy, L., Cullather, R., Draper, C., Gelaro, R. and Suarez, M. (2015) MERRA-2 : Initial Evaluation of the Climate. NASA Technical Report Series on Global Modeling and Data Assimilation, 43, 139.

[22] Rienecker, M.M., Suarez, M.J., Gelaro, R., Todling, R., Bacmeister, J., Liu, E. and Woollen, J. (2011) MERRA: NASA's Modern-Era Retrospective Analysis for Research and Applications. Journal of Climate, 24, 3624-3648. https://doi.org/10.1175/JCLI-D-11-00015.1

[23] Prados, A.I. and Tools, G.V. (2008) Visualization, Exploration , and Model Comparison of Nasa Air Quality Remote Sensing Data via Giovanni. 7 th Annual CMAS Conference, Chapel Hill, 6-8 October 2008, 7-9.

https://www.cmascenter.org/conference/2008/abstracts/prados_visualization_explo ration_cmas08.pdf

[24] Acker, J., Soebiyanto, R., Kiang, R. and Kempler, S. (2014) Use of the NASA Giovanni Data System for Geospatial Public Health Research: Example of Weather-Influenza Connection. ISPRS International Journal of Geo-Information, 3, 1372 1386. https://doi.org/10.3390/ijgi3041372

[25] García, O.E., Expósito, F.J., Díaz, J.P. and Díaz, A.M. (2011) Radiative Forcing under Mixed Aerosol Conditions. Journal of Geophysical Research Atmospheres, 116, 1-12. 